Published in final edited form as:

Am Heart J. 2017 October ; 192: 19-25. doi:10.1016/j.ahj.2017.07.001.

\title{
Galectin-3 and Incidence of Atrial Fibrillation: the Atherosclerosis Risk in Communities (ARIC) Study
}

\author{
Oluwaseun E. Fashanu, MBBS, MPH ${ }^{\mathrm{a}}$, Faye L. Norby, MS, $\mathrm{MPH}^{\mathrm{a}}$, David Aguilar, MD $^{\mathrm{b}}$, \\ Christie M. Ballantyne, MD $^{\mathrm{b}}$, Ron C. Hoogeveen, $\mathrm{PhD}^{\mathrm{b}}$, Lin Y. Chen, MD, $\mathbf{M S}^{\mathrm{c}}$, Elsayed $\mathrm{Z}$. \\ Soliman, $\mathbf{M D}^{\mathrm{d}}$, Alvaro Alonso, MD, $\mathbf{P h D}^{\mathrm{e}}$, and Aaron R. Folsom, MD, MPH ${ }^{\mathrm{a}}{ }^{*}$ \\ aDivision of Epidemiology and Community Health, School of Public Health, University of \\ Minnesota, Minneapolis, Minnesota, USA \\ bDepartment of Medicine, Baylor College of Medicine and Methodist DeBakey Heart and Vascular \\ Center, Houston, Texas, USA \\ ${ }^{\circ}$ Cardiovascular Division, Department of Medicine, University of Minnesota, Minneapolis, \\ Minnesota, USA \\ dEpidemiological Cardiology Research Center, Wake Forest School of Medicine, Winston Salem, \\ North Carolina, USA \\ eDepartment of Epidemiology, Rollins School of Public Health, Emory University, Atlanta, Georgia, \\ USA
}

\begin{abstract}
Background-Galectin-3, a beta-galactoside binding lectin involved in important regulatory roles in adhesion, inflammation, immunity, and fibrosis, may be relevant to atrial fibrillation (AF) etiology.

Methods-We included 8,436 participants free of AF at baseline (1996-98) and with measures of plasma galectin-3 from the Atherosclerosis Risk in Communities (ARIC) study. We ascertained incident AF through 2013 from study visit ECGs, hospitalizations and death certificates.

Multivariable Cox proportional hazards models, adjusted for AF risk factors plus incident HF and CHD, were used to estimate hazard ratios for the association between galectin-3 and incident AF.
\end{abstract}

Results-The mean age (SD) of participants was 62.6 (5.6) years and was comprised of 58.7\% women and $21.2 \%$ blacks. During a median follow-up of 15.7 years, 1,185 incident cases of AF were observed. After adjusting for AF risk factors, participants with galectin-3 levels $290^{\text {th }}$ percentile $(19.5 \mathrm{ng} / \mathrm{mL})$ had a significantly higher risk of incident AF when compared to the

*Corresponding author: Aaron R. Folsom, MD, Division of Epidemiology \& Community Health, School of Public Health, University of Minnesota, 1300 South $2^{\text {nd }}$ Street, Suite 300, Minneapolis, Minnesota 55454, United States. Telephone: (612) 626-8862. Fax: (612) 624-0315. folso001@umn.edu.

Publisher's Disclaimer: This is a PDF file of an unedited manuscript that has been accepted for publication. As a service to our customers we are providing this early version of the manuscript. The manuscript will undergo copyediting, typesetting, and review of the resulting proof before it is published in its final citable form. Please note that during the production process errors may be discovered which could affect the content, and all legal disclaimers that apply to the journal pertain.

Disclosures

The other authors report no conflicts. 
lowest quartile (4.4 - $11.9 \mathrm{ng} / \mathrm{mL})$, with hazard ratios (95\% confidence interval) of 1.40 (1.04 $1.89)$ for the 90th $-<95$ th percentile and $1.51(1.11-2.06)$ for the 95 th -100 th percentile. This association was attenuated and no longer statistically significant after accounting for incident CHD and $\mathrm{HF}$ as time dependent variables.

Conclusions-Elevated plasma galectin-3 is associated with increased risk of incident AF. Galectin-3 may increase AF risk via pathways involving CHD and HF.

\section{Keywords}

Atrial fibrillation; Fibrosis; Galectin-3; Prospective study

Atrial fibrillation (AF) is a common supraventricular tachyarrhythmia. ${ }^{1} \mathrm{AF}$ is associated with increased risk of cardiovascular sequelae, including heart failure, stroke, and premature mortality. ${ }^{2}$ Despite the identification of various risk factors and advancements in the management of $\mathrm{AF}, \mathrm{AF}$ incidence is on the rise and the prevalence may more than double by the year 2050. ${ }^{1,3,4}$ There is, therefore, a need to identify modifiable risk factors that can help predict or offer avenues to mitigate this risk. Galectin-3, a beta-galactoside binding lectin involved in important regulatory roles in adhesion, inflammation, immunity, and fibrosis, 5,6 may be relevant to AF pathogenesis. Inflammation and fibrosis of the myocardium may be particularly important in AF etiology. ${ }^{7}$ Inhibition of galectin-3 has been shown to interfere with myocardial fibrogenesis, and some have suggested it might be a therapeutic target for AF. ${ }^{8}$ Galectin-3 has been associated with atrial remodeling in AF patients ${ }^{9}$ and outcomes after catheter ablation of atrial AF. ${ }^{10,11}$ Recent epidemiologic studies have shown that blood levels of galectin-3 are associated positively with incident heart failure (HF) and coronary heart disease (CHD), ${ }^{6,12-14}$ but to our knowledge, only 2 prospective studies of exclusively whites have tested whether galectin-3 concentrations are associated with incident AF. Both studies reported positive associations that were no longer significant after adjusting for traditional AF risk factors. ${ }^{12,15}$ In the largest prospective study to date, involving whites and blacks, we tested the hypothesis that plasma galectin- 3 concentration is associated positively with the incidence of $\mathrm{AF}$ after controlling for traditional risk factors and that this association would not be explained in its entirety by the association of galectin-3 with HF and CHD. Furthermore, a genome wide association study identified a non-synonymous singlenucleotide polymorphism (SNP) (rs4644) in the galectin-3 encoding gene, LGALS3, to be strongly associated with plasma galectin- 3 concentrations. ${ }^{16} \mathrm{We}$, therefore, also assessed whether the rs4644 in the LGALS3 gene would be associated with $\mathrm{AF}$ incidence.

\section{Methods}

\section{Study population}

The Atherosclerosis Risk in Communities (ARIC) study is a prospective epidemiological study aimed at identifying the risk factors for atherosclerosis and cardiovascular diseases. Participants were recruited between 1987 and 1989 from 4 communities in the United States (Washington County, MD; the northwest suburbs of Minneapolis, MN; Jackson, MS; and Forsyth County, NC). ${ }^{17}$ ARIC consisted of 15,792 men and women aged between 45 to 65 years who were mostly white or black. Since onset, participants have been examined 5 
additional times: visit 2 (1990 - 1992), visit 3 (1993 - 1995), visit 4 (1996 - 1998), visit 5 (2011 - 2013) and visit 6 (2016 - 2017). Participants are being followed by annual or semiannual telephone interviews and active surveillance of ARIC community hospitals. ARIC was approved by the institutional review board of each participating center, and all participants provided written informed consent.

This analysis involved participants who were present at ARIC visit 4. Of 11,656 visit 4 participants, we excluded those who were not white or black due to small numbers, and those with unreadable visit 4 electrocardiograms (ECGs) $(n=243)$. Of the remainder, we excluded those with prevalent AF $(n=297)$, missing galectin-3 measurement $(n=904)$, prevalent HF or CHD $(n=1190)$, or missing covariates $(n=586)$. This left 8,436 participants included in our final analysis.

\section{Atrial fibrillation ascertainment}

Incident cases of AF occurring after ARIC visit 4 (1996 - 1998) until 2013 were identified through ECGs performed during follow-up visit 5, via hospital discharge records, or from death certificates. At visit 5, a 10-second 12-lead ECG was performed on participants with a GE MAC 1200 electrocardiograph (GE Medical Systems, Inc., Milwaukee, WI). ECGs were transmitted to the ARIC ECG reading center where they were coded. All readings coded as AF were reviewed by a cardiologist to confirm the diagnosis. Follow-up calls and review of local hospital discharges were used to identify and obtain information on all hospitalizations. A trained abstractor recorded all ICD-9 hospital discharge codes for the hospitalizations. An ICD-9 code of 427.31 or 427.32 was used to determine the presence of AF. Transient cases of AF occurring after cardiac surgery were excluded. That is, in an effort to limit the outcome to a consistent classification of AF, we excluded AF hospitalization diagnoses occurring simultaneously with heart revascularization surgery (ICD-9 code 36.X) or other cardiac surgery involving heart valves or septa (ICD-9 code 35.X), without evidence of AF in subsequent hospitalizations or study exams. ${ }^{18}$ All deaths due to AF (ICD-10 code I48 or ICD-9 code 427.3) were classified as cases. The validity of this AF ascertainment has been reported to be $84 \%$ sensitive and $98 \%$ specific. ${ }^{18}$ The incidence date of AF was defined as ARIC visit 5 ECG showing AF, the first hospital discharge with AF or atrial flutter, or death by $\mathrm{AF}$, whichever occurred first.

\section{Galectin-3 and risk factor ascertainment}

Galectin-3 was measured using a chemiluminescent microparticle immunoassay on an Architect $i$ 2000sr instrument (Abbott, Abbott Park, IL) in EDTA-plasma samples that were collected at visit 4 and had been stored at $-70^{\circ} \mathrm{C}$ prior to analysis. The measurements were performed July 2015 - February 2016. The Architect galectin-3 assay has a limit of detection of $1.1 \mathrm{ng} / \mathrm{mL}$ and a limit of quantitation of $4.0 \mathrm{ng} / \mathrm{mL}$. Interassay coefficients of variation were $5.2 \%, 3.3 \%$, and $2.3 \%$ at mean galectin-3 levels of $8.8 \mathrm{ng} / \mathrm{mL}, 19.2 \mathrm{ng} / \mathrm{mL}$ and $72.0 \mathrm{ng} / \mathrm{ml}$, respectively. At the time of blood processing, 402 participants' plasma specimens were split, masked, and sent to the laboratory to assess galectin-3 laboratory reliability. The reliability coefficient was $r=0.92$ and coefficient of variation, $(\mathrm{CV})=7.5 \%$. After removing 7 potentially mislabeled "outlier" samples these respective values were $\mathrm{r}=0.95$ and $\mathrm{CV}=5.7 \%$. 
At visit 4, participants reported their race, use of antihypertensive medications within the previous 2 weeks, and smoking status. Blood pressure was measured with the use of a random-zero sphygmomanometer. The average of 2 readings which were taken after the participant had rested for 5 minutes was used. Height and body mass index (BMI) were measured. ${ }^{19}$ Diabetes mellitus was defined as fasting glucose $\geq 126 \mathrm{mg} / \mathrm{dL}(7.0 \mathrm{mmol} / \mathrm{L})$, nonfasting glucose $\geq 200 \mathrm{mg} / \mathrm{dL}$ ( $11.1 \mathrm{mmol} / \mathrm{L})$, treatment for diabetes mellitus, or selfreported physician diagnosis of diabetes mellitus. Total cholesterol, estimated glomerular filtration rate (eGFR), N-terminal pro-B-type natriuretic peptide (NT-proBNP), C-reactive protein (CRP), and Troponin $\mathrm{T}$ ( $\mathrm{TnT}$ ) were measured from blood samples as described previously. ${ }^{20-22}$ Ascertainment and definitions of prevalent and incident HF and CHD have been described. ${ }^{19,23}$ The rs4644 SNP genotying was performed using the HumanExome BeadChip Array. ${ }^{24}$

\section{Statistical analysis}

Statistical analyses were performed using SAS 9.4 (SAS Institute Inc., Cary, NC) and STATA, version 12 (Stata, College Station, TX). Baseline characteristics of participants were described by galectin-3 quartiles. Multivariable Cox proportional hazards models were used to estimate hazard ratios (HRs) for the association between galectin-3 and incident AF. Models included galectin-3 in categories ( $0 \%-<25 \%, 25 \%-<50 \%, 50 \%-<75 \%, 75 \%-$ $<90 \%, 90 \%-<95 \%$, and $95 \%-100 \%$ ) due to no a priori set cut point, and as a natural log transformed variable. Models were adjusted for age (years), race (white, black), sex (female, male), systolic blood pressure (mmHg), blood pressure medications (yes, no), BMI ( $\left.\mathrm{kg} / \mathrm{m}^{2}\right)$, height (meters), diabetes status (yes, no), total cholesterol (mg/dL), smoking status (current, former, never), eGFR (mL/min per $1.73 \mathrm{~m}^{2}$ ), rs4644 genotype (CC, AC, AA), ln NTproBNP $(\ln \mathrm{pg} / \mathrm{mL}), \ln \mathrm{CRP}(\ln \mathrm{mg} / \mathrm{l})$, and $\ln \mathrm{TnT}(\ln \mathrm{ng} / \mathrm{L})$. We verified that the proportional hazards assumption was not violated by testing the interaction of log follow-up time with galectin-3 $(\mathrm{p}=0.66)$. Cubic splines, adjusted for age, sex and race with 5 knots at the $5^{\text {th }}$, $27.5^{\text {th }}, 50^{\text {th }}, 72.5^{\text {th }}$ and $95^{\text {th }}$ percentiles, were used to characterize the association between galectin- 3 and AF incidence. Because the regression analysis and spline graphs showed the association mainly restricted to the highest galectin-3 levels, we ultimately split the highest quartile into 3 categories and compared them to the lowest quartile (referent group). The test for linear trend was derived after assigning the median value of each category of galectin-3 and modeling as a continuous variable. We tested for interactions between age, sex, race, and galectin-3. Only the age by galectin-3 interaction was significant ( $\mathrm{p}=0.03$ ); yet, after dichotomizing age by the median and adjusting for age as a categorical variable, the interaction was modest and no longer significant $(\mathrm{p}=0.14)$.

In a secondary analysis, we assessed the association between galectin- 3 and incident $\mathrm{AF}$ adjusting for interim $\mathrm{HF}$ and $\mathrm{CHD}$ as time dependent covariates. In another analysis, we assessed for time dependency of the association between galectin- 3 and incident AF by categorizing the follow-up time into three time periods $(0-8$ years, $>8-13$ years, and $>13$ years).

We also examined the race-specific associations of the LGALS3 rs4644 genotype (CC, AC, and AA) with AF incidence using Cox models. For each participant, we coded the SNP as 
having 0 (CC), 1 (AC), or 2 (AA) copies of the minor allele and used an additive genetic model. For the analysis in blacks, we also adjusted for 10 principal components of ancestry.

The Atherosclerosis Risk in Communities (ARIC) study is carried out as a collaborative study supported by the National Heart, Lung, and Blood Institute (NHLBI) contracts (HHSN268201100005C, HHSN268201100006C, HHSN268201100007C, HHSN268201100008C, HHSN268201100009C, HHSN268201100010C, HHSN268201100011C, and HHSN268201100012C). Abbott Diagnostics provided funding for the galectin-3 measurements. Dr. Alonso was supported by American Heart Association grant 16EIA26410001. The authors are solely responsible for the design and conduct of this study, all study analyses, the drafting and editing of the paper and its final contents.

\section{Results}

At the ARIC visit 4 baseline, among 8,436 study participants (58.7\% women, 21.2\% black, and mean age $=62.6$ years), mean galectin- 3 levels were found to be significantly higher in women $(15.4 \mathrm{ng} / \mathrm{mL})$ than men $(13.5 \mathrm{ng} / \mathrm{mL})(\mathrm{p}<0.0001)$ and in black participants $(15.6$ $\mathrm{ng} / \mathrm{mL})$ than whites $(14.4 \mathrm{ng} / \mathrm{mL})(\mathrm{p}<0.0001)$. Galectin-3 was also associated with all AF risk factors except current smoking status (Table I).

There was a total of 1,185 incident cases of AF during the follow-up period 1996-2013 (118,558 person-years). Because our analysis and spline graphs (Figure 1) showed the association restricted to the highest levels, we ultimately split the highest quartile into 3 groups and presented galectin-3 levels in percentiles (Table II). (See supplementary material for association between galectin-3 quartiles and incident AF.) In model 1, adjusted for age, race and sex, participants with galectin- 3 levels $\geq 75^{\text {th }}$ percentile $(\geq 16.7 \mathrm{ng} / \mathrm{mL}$ ) had a significantly higher risk of incident AF when compared to the lowest quartile (4.4 - $11.9 \mathrm{ng} /$ $\mathrm{mL})$, with HRs (95\% confidence intervals) of $1.30(1.07-1.57)$ for the $75^{\text {th }}-<90^{\text {th }}$ percentile, $1.75(1.35-2.26)$ for the $90^{\text {th }}-<95^{\text {th }}$ percentile, and $2.35(1.86-2.99)$ for the $95^{\text {th }}-100^{\text {th }}$ percentile ( $\mathrm{p}$ for trend $<0.0001$, Table II). The galectin- 3 association was somewhat attenuated but the trend remained statistically significant after adjusting for other risk factors in model 2, with HRs $(95 \% \mathrm{CI})=1.37(1.05-1.78)$ for the $90^{\text {th }}-<95^{\text {th }}$ percentile and $1.67(1.29-2.16)$ for the $95^{\text {th }}-100^{\text {th }}$ percentile $(\mathrm{p}$ for trend $=0.0004)$. After further adjusting for rs4644 genotype in model 3, the galectin-3 HRs $(95 \% \mathrm{CI})$ were 1.63 $(1.21-2.20)$ for the $90^{\text {th }}-<95^{\text {th }}$ percentile, and $2.02(1.49-2.73)$ for the $95^{\text {th }}-100^{\text {th }}$ percentile ( $\mathrm{p}$ for trend $<0.0001$ ), and after further adjusting for cardiac biomarkers in model 4 , galectin-3 HRs $(95 \% \mathrm{CI})$ were $1.40(1.04-1.89)$ for the $90^{\text {th }}-<95^{\text {th }}$ percentile and 1.50 $(1.10-2.05)$ for the $95^{\text {th }}-100^{\text {th }}$ percentile $(\mathrm{p}$ for trend $=0.004)$. When expressed as a continuous variable, the HRs $(95 \% \mathrm{CI})$ for AF per 1 unit increment in ln galectin-3 were 2.01 (1.59-2.53), $1.33(1.04-1.71), 1.70(1.24-2.32)$, and $1.03(0.77-1.39)$ for models 1 -4 , respectively (not shown).

In a secondary analysis, a total of 935 incident $\mathrm{HF}$ and 644 incident CHD events occurred during follow-up and before the occurrence of AF. After accounting for incident CHD and $\mathrm{HF}$ as time dependent variables while adjusting for covariates in model 4 , the association between galectin-3 concentration and incident AF was attenuated and no longer statistically 
significant. The model 4 HR $\left(95 \%\right.$ CI) for galectin- $3 \geq 95^{\text {th }}$ percentile versus the lowest quartile fell from $1.50(1.10-2.05)$ in Table II to $1.11(0.81-1.52)$ ( $\mathrm{p}$ for trend $=0.24$, Table III).

The association between galectin-3 and incident AF appeared to be strongest during the first 8 years of follow-up. The HRs (95\% CI) per 1 unit increment in ln galectin-3 were 2.29 $(1.40-3.74), 0.96(0.58-1.61)$, and $0.99(0.56-1.75)$ for follow-up times of $0-8$ years, > $8-13$ years, and $>13$ years, when adjusted for variables in model 3 .

The frequencies of having 0,1 , or 2 copies of the A allele were $34.6 \%, 48.3 \%$, and $17.1 \%$ in whites and $52.6 \%, 40.0 \%$, and $7.5 \%$ in blacks. The mean galectin- 3 concentrations decreased across those with 0,1 , or 2 copies: $16.7 \mathrm{ng} / \mathrm{mL}, 13.9 \mathrm{ng} / \mathrm{mL}$, and $11.1 \mathrm{ng} / \mathrm{mL}$ (p for trend $<0.0001$ ) for whites and $17.3 \mathrm{ng} / \mathrm{mL}, 14.2 \mathrm{ng} / \mathrm{mL}$, and $11.6 \mathrm{ng} / \mathrm{mL}$ ( $\mathrm{p}$ for trend $<0.0001)$ for blacks. The hazard ratios $(95 \% \mathrm{CI})$ for AF in whites were $0.95(0.82-1.09)$ for the AC genotype, and $1.10(0.92-1.31)$ for the AA genotype compared to the CC genotype when adjusted for participants age and sex ( $\mathrm{p}$ for trend $=0.46$ ). In blacks, with additional adjustment for the 10 principal components of ancestry, these HRs (95\% CI) were $0.88(0.64$ $-1.21)$ and $0.75(0.40-1.41)$ for the $\mathrm{AC}$ and AA genotypes respectively ( $\mathrm{p}$ for trend $=0.28$ ) (supplemental table III).

\section{Discussion}

In this large prospective population-based study, we found that high levels of plasma galectin-3 were associated with an increased risk of AF over a median follow-up period of 15.7 years, and that the $L G A L S 3$ rs 4644 minor allele was associated with lower galectin-3 levels in both whites and blacks but not associated with increased risk of incident AF.

The association between plasma galectin- 3 and AF was moderately strong and independent of baseline AF risk factors and several biomarkers associated with AF. However, this association was accounted for by participants with high galectin-3 levels having developed more HF and CHD during follow-up before AF. The observed association may be explained by the role of galectin-3 in myocardial fibrosis. Activated macrophages secrete galectin-3, which leads to the activation and proliferation of fibroblasts, collagen deposition, and subsequent cardiac fibrosis and myocyte dysfunction. ${ }^{5,25}$ This cascade predisposes to AF, which further leads to more macrophage activation and perpetuation of this vicious cycle. 5,25

Clinical evidence supports a role of galectin-3 in AF. Galectin-3 has been associated with atrial remodeling in $\mathrm{AF}$ patients ${ }^{9}$, with $\mathrm{AF}$ recurrence in patients who have undergone ablation, ${ }^{11}$ with cardiometabolic disease ${ }^{26}$, and with $\mathrm{AF}$ prevalence in case-control studies. ${ }^{9,27,28}$ On the other hand, 2 prior prospective epidemiological studies failed to find an independent association between galectin-3 levels and the incidence of AF. ${ }^{12,15}$ In both studies, higher galectin-3 concentrations were associated with an increased risk of AF in individuals in unadjusted analyses, but not after adjustment for other AF risk factors. Differences among existing studies may be attributed to several factors. We had a larger sample size $(n=8,436)$ than the Framingham Offspring study ${ }^{15}(\mathrm{n}=3306)$ and the PREVEND study $^{12}(\mathrm{n}=5958)$. Both previous prospective studies had a younger study population and 
shorter median follow-up times and therefore fewer incident cases of AF (Framingham Offspring study ( $n=250)$, PREVEND $(n=225)$ ) than our study $(n=1,185)$. These would have given ARIC greater statistical power to detect an independent association, and the AF association was not linear and only apparent at high galectin-3 concentrations. In addition, prior to our study, no investigation had accounted for interim heart failure and coronary heart disease as possibly mediating a galectin- 3 and AF association, a possibility also mentioned by Ho et al in the Framingham Offspring study. ${ }^{15}$

The LGALS3 rs4644 minor allele was associated with lower mean levels of galectin-3. Blacks had a lower frequency of the minor allele than did whites and, correspondingly, a higher mean plasma galectin-3 concentration. However, this SNP has been shown to lie within or near the epitopes of the binding region for the antibody used for our galectin-3 assay. ${ }^{16}$ This might affect the affinity of the antibody and therefore, the race-related relationship with galectin-3 levels may be artefactual. Adjustment for this SNP in our models slightly strengthened the association between plasma galectin-3 and AF.

A limitation of our study is that we had a single measure of galectin-3, in contrast with the PREVEND study ${ }^{12}$ which had 2 measurements of galectin- 3 levels about 4 years apart. A second consideration is that galectin-3 measurements were made on samples stored for years. Although our lab QC and blinded QC data indicate excellent assay performance, we cannot rule out that sample degradation may have affected galectin-3 measurements. However, if sample integrity was a factor we would have expected this to lead to a significant reduction in the power of our analyses, and increase the likelihood of the null finding. Also, galectin-3 concentrations appear to be stable after storage for at least 6 months. ${ }^{13}$ Finally, galectin-3 levels may change prior to the AF occurrence, which we could not document with a single measure.

Another limitation to this study may be some misclassification of AF. AF cases were ascertained via hospital discharge codes and during visit 5 follow-up ECG examinations. Since $99 \%$ of our incident AF cases were ascertained through hospitalization records containing ICD-9 code 427.31 or 427.32 , we unfortunately have no way to distinguish the type of AF presentation. In addition, we likely missed some paroxysmal cases of AF managed in the outpatient setting or other AF cases who had not presented to the hospital or for visit 5 follow-up examinations. However, it has been shown that the incidence rates of AF in the ARIC study are consistent with other population-based studies, and the validity of AF ascertainments using hospitalizations is acceptable. Also, making use of the hospitalization codes may have resulted in some false positives. In a sample of 125 discharge summaries, we were only able to confirm $89 \%$ of AF cases in ARIC. ${ }^{18}$

In conclusion, high galectin-3 levels are associated with an increased incidence of AF in the general population via pathways seemingly involving CHD and HF. The LGALS3 rs 4644 SNP, though associated with mean galectin-3 levels, was not associated with AF incidence in either whites or blacks. Future work in independent cohorts should determine the value of galectin-3 measurements for risk stratification and prediction of new-onset AF beyond established risk factors and biomarkers. 


\section{Supplementary Material}

Refer to Web version on PubMed Central for supplementary material.

\section{Acknowledgments}

The authors thank the staff and participants of the ARIC Study for their important contributions.

Dr. Ballantyne has received research grant to institution from Abbott Diagnostics and consults with Abbott.

\section{References}

1. Wadke R. Atrial fibrillation. Dis Mon. 2013; 59:67-73. [PubMed: 23410667]

2. Ball J, Carrington MJ, McMurray JJV, et al. Atrial fibrillation: profile and burden of an evolving epidemic in the $21^{\text {st }}$ century. Int J Cardiol. 2013; 167:1807-1824. [PubMed: 23380698]

3. Miyasaka Y, Barnes ME, Gersh BJ, et al. Secular trends in incidence of atrial fibrillation in Olmsted County, Minnesota, 1980 to 2000, and implications on the projections for future prevalence. Circulation. 2006; 114:119-125. [PubMed: 16818816]

4. Colilla S, Crow A, Petkun W, et al. Estimates of current and future incidence and prevalence of atrial fibrillation in the U.S. adult population. Am J Cardiol. 2013; 112:1142-1147. [PubMed: 23831166]

5. Jalife J. Mechanisms of persistent atrial fibrillation. Curr Opin Cardiol. 2014; 29:20-27. [PubMed: 24281345]

6. de Boer RA, Voors AA, Muntendam P, et al. Galectin-3: a novel mediator of heart failure development and progression. Eur J Heart Fail. 2009; 11:811-817. [PubMed: 19648160]

7. Schotten U, Verheule S, Kirchhof P, et al. Pathophysiological mechanisms of atrial fibrillation: a translational appraisal. Physiol Rev. 2011; 91:265-325. [PubMed: 21248168]

8. Takemoto Y, Ramirez RJ, Yokokawa M, et al. Galectin-3 regulates atrial fibrillation remodeling and predicts catheter ablation outcomes. JACC Basic Transl Sci. 2016; 1:143-154. [PubMed: 27525318]

9. Sonmez O, Ertem FU, Vatankulu MA, et al. Novel fibro-inflammation markers in assessing left atrial remodeling in non-valvular atrial fibrillation. Med Sci Monit. 2014; 20:463-470. [PubMed: 24651058]

10. Kornej J, Schmidl J, Ueberham L, et al. Galectin-3 in patients with atrial fibrillation undergoing radiofrequency catheter ablation. PloS One. 2015; 10:e0123574. [PubMed: 25875595]

11. Clementy N, Benhenda N, Piver E, et al. Serum galectin-3 levels predict recurrences after ablation of atrial fibrillation. Sci Rep. 2016; 6:34357. [PubMed: 27677964]

12. van der Velde AR, Meijers WC, Ho JE, et al. Serial galectin-3 and future cardiovascular disease in the general population. Heart. 2016; 102:1134-1141. [PubMed: 27084804]

13. Christenson RH, Duh S-H, Wu AHB, et al. Multi-center determination of galectin-3 assay performance characteristics: Anatomy of a novel assay for use in heart failure. Clin Biochem. 2010; 43:683-690. [PubMed: 20153309]

14. Djousse L, Matsumoto C, Petrone A, et al. Plasma galectin 3 and heart failure risk in the Physicians' Health Study. Eur J Heart Fail. 2014; 16:350-354. [PubMed: 24464746]

15. Ho JE, Yin X, Levy D, et al. Galectin 3 and incident atrial fibrillation in the community. Am Heart J. 2014; 167:729-734. e721. [PubMed: 24766984]

16. de Boer RA, Verweij N, van Veldhuisen DJ, et al. A genome-wide association study of circulating galectin-3. PloS One. 2012; 7:e47385. [PubMed: 23056639]

17. ARIC Investigators. The Atherosclerosis Risk in Communities (ARIC) study: design and objectives. Am J Epidemiol. 1989; 129:687-702. [PubMed: 2646917]

18. Alonso A, Agarwal SK, Soliman EZ, et al. Incidence of atrial fibrillation in whites and AfricanAmericans: the Atherosclerosis Risk in Communities (ARIC) study. Am Heart J. 2009; 158:111117. [PubMed: 19540400] 
19. Norby FL, Soliman EZ, Chen LY, et al. Trajectories of cardiovascular risk factors and incidence of atrial fibrillation over a 25-year follow-up: The ARIC Study (Atherosclerosis Risk in Communities). Circulation. 2016; 134:599-610. [PubMed: 27550968]

20. Whelton SP, Roy P, Astor BC, et al. Elevated high-sensitivity C-reactive protein as a risk marker of the attenuated relationship between serum cholesterol and cardiovascular events at older age. The ARIC Study. Am J Epidemiol. 2013; 178:1076-1084. [PubMed: 24026395]

21. Folsom AR, Lutsey PL, Astor BC, et al. Chronic kidney disease and venous thromboembolism: a prospective study. Nephrol Dial Transplant. 2010; 25:3296-3301. [PubMed: 20353958]

22. Folsom AR, Nambi V, Bell EJ, et al. Troponin T, NT-pro BNP, incidence of stroke: The Atherosclerosis Risk in Communities (ARIC) Study. Stroke. 2013; 44:961-967. [PubMed: 23471272]

23. Chambless LE, Folsom AR, Sharrett AR, et al. Coronary heart disease risk prediction in the Atherosclerosis Risk in Communities (ARIC) study. J Clin Epidemiol. 2003; 56:880-890. [PubMed: 14505774]

24. Grove ML, Yu B, Cochran BJ, et al. Best practices and joint calling of the HumanExome BeadChip: the CHARGE Consortium. PloS One. 2013; 8:e68095. [PubMed: 23874508]

25. Lippi G, Cervellin G, Sanchis-Gomar F. Galectin-3 in atrial fibrillation: Simple bystander, player or both? Clin Biochem. 2015; 48:818-822. [PubMed: 25952321]

26. Nayor M, Wang N, Larson MG, et al. Circulating galectin-3 is associated with cardiometabolic disease in the community. J Am Heart Assoc. 2016; 5:e002347.

27. Chen D, Procter N, Goh V, et al. New onset atrial fibrillation is associated with elevated galectin-3 levels. Int J Cardiol. 2016; 223:48-49. [PubMed: 27529590]

28. Szadkowska I, Wlazel RN, Migala M, et al. The association between galectin-3 and clinical parameters in patients with first acute myocardial infarction treated with primary percutaneous coronary angioplasty. Cardiol J. 2013; 20:577-582. [PubMed: 24338533] 

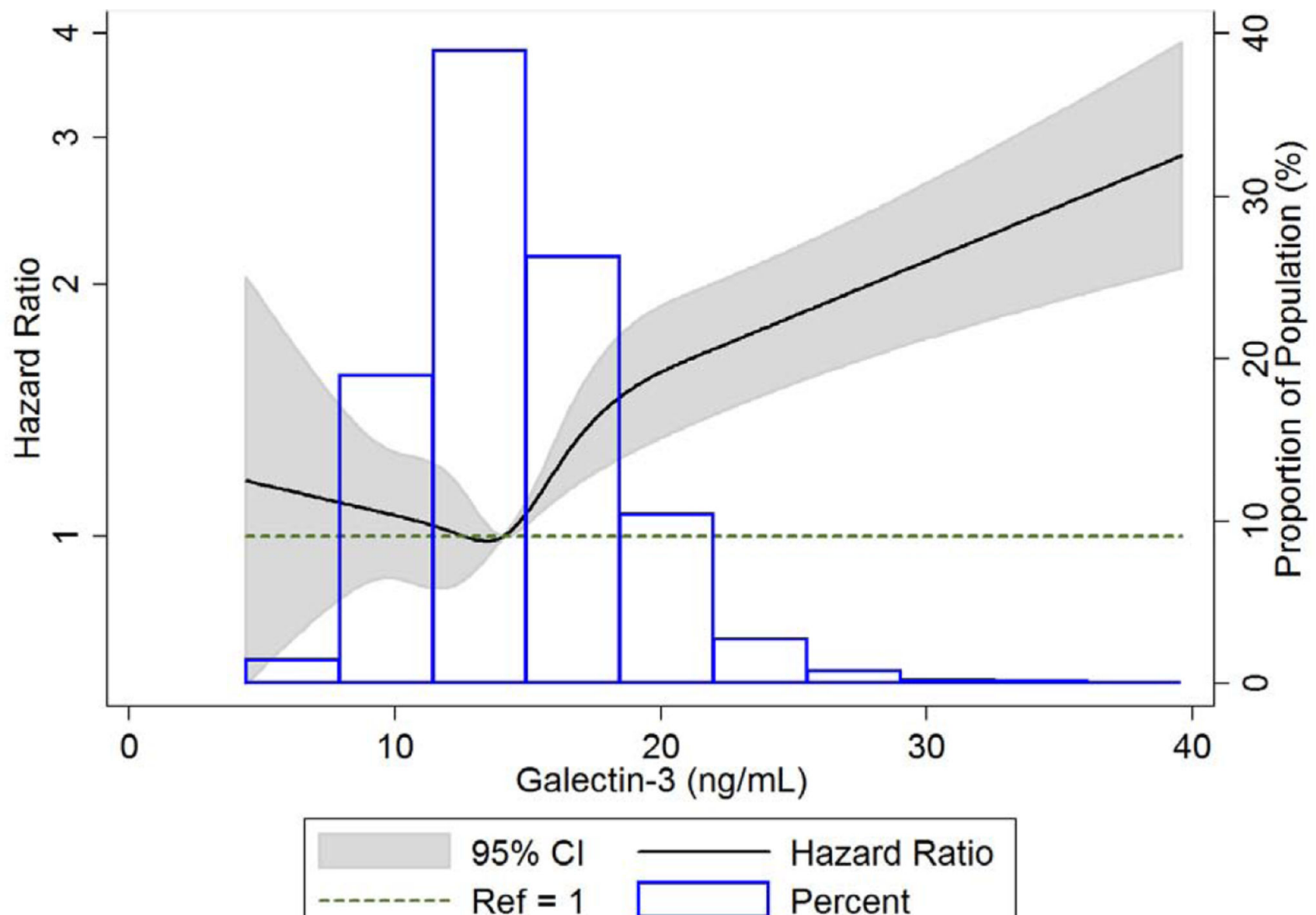

Figure 1.

Cubic spline showing association of galectin-3 with atrial fibrillation incidence in ARIC 1996 - 2013. High extreme values of galectin-3 (> $40 \mathrm{ng} / \mathrm{ml})$ were excluded $(n=18)$ from the spline analysis to obtain estimates. The median value $(14.1 \mathrm{ng} / \mathrm{ml})$ was used as reference in a Cox proportional hazards model adjusted for age, sex, and race. The knots were placed at the $5^{\text {th }}, 27.5^{\text {th }}, 50^{\text {th }}, 72.5^{\text {th }}$ and $95^{\text {th }}$ percentiles. 


\section{Table I}

Baseline characteristics of participants stratified by galectin-3 quartiles, ARIC, 1996 - 1998.

\begin{tabular}{|c|c|c|c|c|}
\hline \multirow[b]{2}{*}{ Characteristics ${ }^{*}$} & \multicolumn{4}{|c|}{ Galectin-3 (ng/mL) } \\
\hline & $\begin{array}{c}\text { Q1 } \\
(4.4-11.9)\end{array}$ & $\begin{array}{c}Q 2 \\
(12.0-14.1)\end{array}$ & $\begin{array}{c}\text { Q3 } \\
(14.2-16.6)\end{array}$ & $\begin{array}{c}\text { Q4 } \\
(16.7-114.0)\end{array}$ \\
\hline $\mathrm{N}$ & 2126 & 2130 & 2049 & 2131 \\
\hline Age (years) & $61.4(5.4)$ & $62.2(5.6)$ & $62.7(5.6)$ & $64.0(5.7)$ \\
\hline Sex (\% male) & 58.9 & 46.8 & 35.0 & 24.4 \\
\hline Race (\% black) & 16.5 & 19.4 & 21.7 & 27.2 \\
\hline $\mathrm{SBP}(\mathrm{mmHg})$ & $125(18)$ & $126(19)$ & $127(19)$ & $129(20)$ \\
\hline Antihypertensive medication (\%) & 29.3 & 32.8 & 37.5 & 52.5 \\
\hline BMI $(\mathrm{kg} / \mathrm{m} 2)$ & $27.9(4.7)$ & $28.0(5.0)$ & $28.8(5.6)$ & $29.8(6.4)$ \\
\hline Height (m) & $1.70(0.09)$ & $1.68(0.09)$ & $1.67(0.09)$ & $1.65(0.09)$ \\
\hline Diabetes $(\%)$ & 13.4 & 11.9 & 14.6 & 17.8 \\
\hline Total cholesterol (mg/dL) & $198(34)$ & $201(36)$ & $203(36)$ & 204 (37) \\
\hline Current smoker $(\%)$ & 14.3 & 15.7 & 13.4 & 14.5 \\
\hline eGFR $\left(\mathrm{ml} / \mathrm{min}\right.$ per $\left.1.73 \mathrm{~m}^{2}\right)$ & $92(14)$ & $89(14)$ & $86(15)$ & $78(18)$ \\
\hline $\mathrm{CRP}(\mathrm{mg} / \mathrm{L})^{\dagger}$ & $1.6(0.8-3.7)$ & $2.0(1.0-4.4)$ & $2.6(1.2-5.5)$ & $3.8(1.6-7.5)$ \\
\hline Troponin $\mathrm{T}(\mathrm{ng} / \mathrm{L})^{\dagger}$ & $5.0(3.0-7.0)$ & $5.0(3.0-7.0)$ & $4.0(3.0-7.0)$ & $5.0(3.0-8.0)$ \\
\hline NT-proBNP $(\mathrm{pg} / \mathrm{mL})^{\dagger}$ & $51(25-100)$ & $61(29-115)$ & $63(33-113)$ & $82(41-147)$ \\
\hline
\end{tabular}

BMI: body mass index; CRP: C-reactive protein; eGFR: estimated glomerular filtration rate; NT-proBNP: N-terminal pro-B-type natriuretic peptide: SBP: systolic blood pressure.

* Values are mean (standard deviation) for continuous variables and percentages for categorical variables unless otherwise specified.

${ }^{\dagger}$ Data are expressed as median $\left(25^{\text {th }}\right.$ percentile $-75^{\text {th }}$ percentile $)$ 


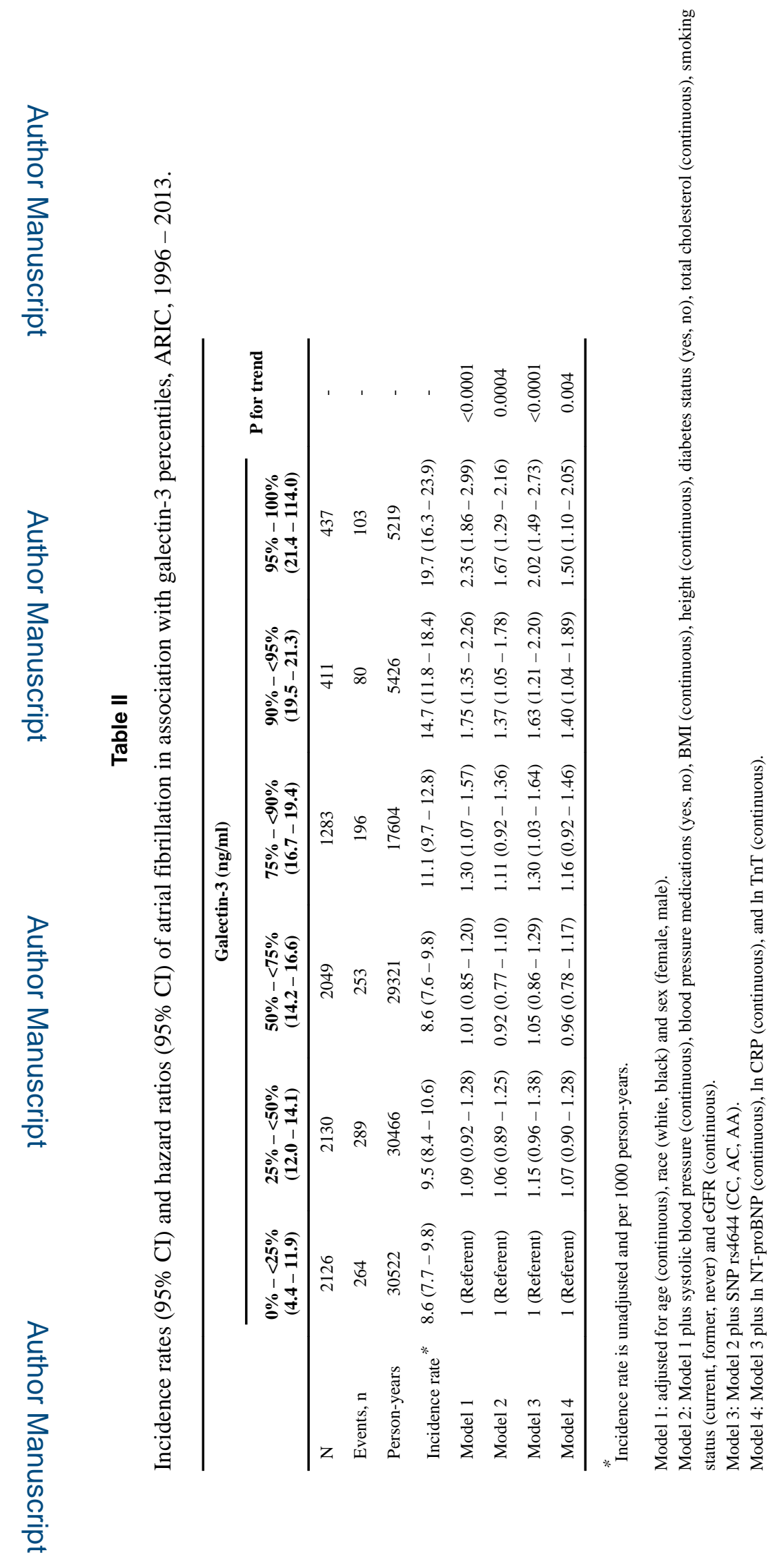

Am Heart J. Author manuscript; available in PMC 2018 October 01. 


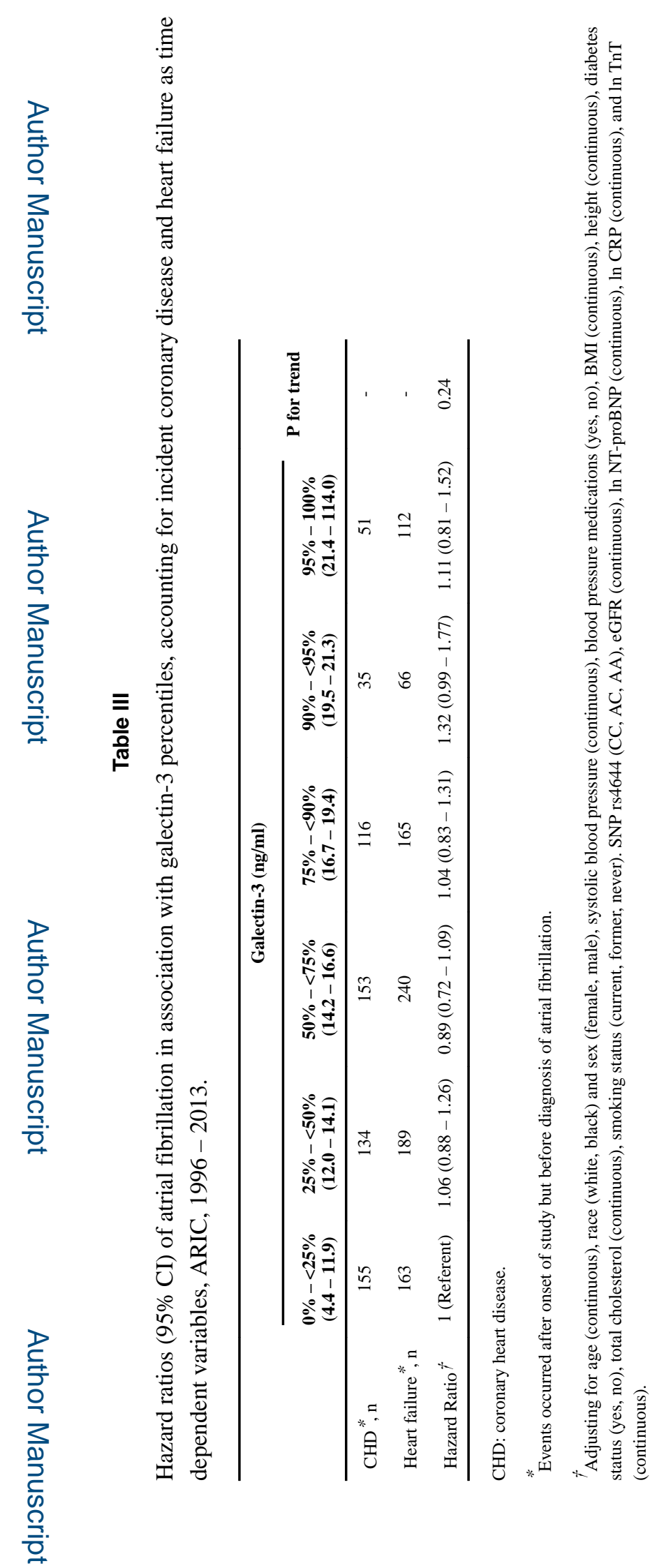

Am Heart J. Author manuscript; available in PMC 2018 October 01. 